\title{
Awareness and compliance to anti-smoking law in South Bengaluru, India
}

\author{
Pradeep S Banandur' , Muthkur V Kumar', Gururaj Gopalkrishna'
}

\begin{abstract}
INTRODUCTION Tobacco smoke affects the health of non-smokers by exposure to second-hand smoke (SHS). The Indian Cigarettes and Other Tobacco Products (COTPA) Act 2003 Section 4 aims to reduce exposure to SHS. Awareness and compliance to COTPA are key to achieving its intended outcome. We assessed: a) awareness among persons responsible for compliance (PRC) and authorized officers (AO), and b) compliance of public places to COTPA in South Bengaluru, India.

METHODS A cross-sectional assessment of public places in South Bengaluru was conducted using time-location sampling. The Johns Hopkins Bloomberg School of Public Health's observational and interview checklist was used to assess compliance of public places to COTPA and awareness of COTPA among PRC/AO, respectively.

RESULTS Among 359 public places, one-third of the public places showed complete (1.9\%) or partial compliance (28.1\%). The majority (93\%) of the PRCs and all AOs were aware of COTPA. However, they lacked information on the different provisions of the Act. Violations like persons smoking (3.9\%), visible ashtrays (6\%) and cigarette butts (13\%) were noted more among eateries compared to other public places. Among those public places supposed to have designated smoking-areas, only 19\% complied.

CONCLUSIONS This is the first representative survey of awareness and compliance of COTPA in Bengaluru City. Low compliance, coupled with the lack of appropriate awareness among PRCs and AOs about COTPA, demands a comprehensive strategy to enhance awareness. Comprehensive efforts towards making all stakeholders understand the health impacts of smoking, and strict enforcement, might facilitate effective implementation of COTPA.
\end{abstract}

\section{AFFILIATION \\ 1 National Institute of Mental Health and Neuro Sciences (NIMHANS), Bengaluru, India \\ CORRESPONDENCE TO \\ Pradeep S Banandur. National Institute of Mental Health and Neuro Sciences (NIMHANS) 560029 Bengaluru, India. E-mail: doctorpradeepbs@gmail. com \\ KEYWORDS \\ compliance, tobacco control, anti-smoking law, COTPA Act 2003}

Received: 24 October 2016 Revised: 1 July 2017

Accepted: 21 August 2017

\section{INTRODUCTION}

Tobacco use is the single most preventable cause of premature death in the world ${ }^{1}$. In India, more than a million people die every year due to tobacco consumption and about 5500 youth initiate the use of tobacco every day ${ }^{2}$. Consumption of tobacco imposes enormous direct and indirect economic losses across States in India 2 .

In addition, tobacco smoke also affects the health of nonsmokers by exposure to second-hand smoke (SHS) ${ }^{4-6}$. The ill effects of exposure to SHS are well established. SHS is also known to cause cancers, respiratory illnesses and heart disease. Globally, exposure to SHS causes 0.6 million deaths each year ${ }^{7}$. According to the Global Adult Tobacco-Survey for India, $52 \%$ of Indian adults are exposed to SHS at home and almost $26 \%$ at the workplace. In Karnataka, $44.3 \%$ of adults are exposed to SHS at home ${ }^{8}$.

Exposure to second-hand smoke (SHS) is a major risk factor for disease and disability among 93\% of the world's population who are still not covered by $100 \%$ smoke-free public health policies ${ }^{7}$. The Cigarettes and Other Tobacco Products (Prohibition of Advertisement and Regulation of Trade and Commerce, Production, Supply and Distribution) Act (COTPA) was enacted in the Indian parliament in $2004^{9}$, to address the exposure to second-hand smoking, and to regulate tobacco advertising, promotion, sponsorship and sale of tobacco products to or by minors. There are 33 Sections in the Act. The provisions of Section 4 relate to prohibition of 
smoking in public places. Any place to which the public has access, whether as of a right or not, and includes auditorium, hospital buildings, railway waiting rooms, amusement centres, restaurants, public offices, court buildings, educational institutions, libraries, public conveyances and the like, which are visited by general public ${ }^{9}$, are defined as a public place by the COTPA Act. As per the provisions of the Act, hotel or accommodation facilities having 30 or more rooms, restaurants or eateries having a seating capacity of 30 persons or more, and airports, need to have a designated smoking-area.

Even though the Act came into effect in 2004, the focus on implementing the Act remained low. Evidence from formal assessments on the compliance to the smoke-free legislation in India, showed partial compliance to the smoke-free legislation in hospital buildings (37\%), office buildings (26.7\%), public places outside hospital buildings (14.3\%) and residential areas $(11.4 \%)^{10,11}$.

In addition to compliance being an issue related to enforcement and political will, compliance to the smoke-free legislation is a behavioural issue. Success of compliance to the smoke-free legislation depends on the willingness of persons responsible for compliance (PRC) to comply with the Act, in addition to awareness among authorized officers $(\mathrm{AO})^{9}$ responsible for the implementation of the Act. PRCs include heads of all government departments at State level, local bodies, including Panchayat Raj Institutions (Local self-government), and all those in-charge of public places, that provide access to public gatherings, such as bus stands, railway stations, markets, parks, religious places, monuments and such places. Within the private sector, PRCs include owners and managers of different public places (hotels, bars, restaurants, eateries, shops and markets), managers of malls and multiplexes, all private offices including private practices (clinics, nursing homes and hospitals). Authorised officers include police officers, health inspectors, excise officers, inspectors of factories and boilers who are government officers under jurisdiction for these public places. Understanding the challenges to comply with the Act, and identifying solutions that are feasible and pragmatic are needed to progress towards a smoke-free society. Compliance assessment is an effective means of measuring progress towards a smokefree society ${ }^{10}$. Thus, we undertook a study to assess the compliance to the smoke-free legislation of the Cigarettes and Other Tobacco Products Act (COTPA), in various public places and to assess awareness among PRC and AO under the Act, in the jurisdiction of the South Zone of Bruhat Bengaluru Mahanagara Palike (BBMP) (Local self-government).

\section{METHODS}

We conducted a cross-sectional study between January to April 2015 among the public places licensed by the respective departments in the South Zone of Bruhat Bengaluru Mahanagara Palike (BBMP). All licensed public places, as defined by COTPA, within the South Zone BBMP formed the sampling frame. Sample size for the study was 362 public places from the finite list of 4507 public places in South Zone BBMP. Sample size was estimated assuming a compliance rate of $50 \%$ to Section 4 of COTPA, with power of $90 \%$, absolute error $5 \%$, and an assumed design effect of 1.4. Sample size was calculated using CDC-Epi Info Version 7 software $^{13}$. A total of 91, 116, 78, 65 and 9 public places were selected for observation in clusters 1 to 5 , respectively (table 1 ).

Data collection involved both observation of public places and looking for direct and indirect evidence of smoking. The number of public places to be observed in each category was determined using a proportionate-to-population sizetechnique. The final numbers were rounded off to the nearest higher whole number (Table 1). A final list of public places within each category was drawn using simple random sampling by computer-generated random numbers.

Since different public places operate at different times of the day, and smoking habits of people might vary depending on the time of the day, we performed time-location sampling to identify the time of observation for a particular public place. Time-location sampling is a recognized sampling method utilized when the variables to be studied are likely to vary at different points of time in a day ${ }^{12}$.

Five different observation time-clusters were used in the study; Cluster 1: 9.00 - 11.59 am, Cluster 2: 12.00 noon - 2.59 pm, Cluster 3: 3.00 - 5.59 pm, Cluster 4: $6.00-8.59$ pm, and Cluster 5: 9.00 - 11.00 pm. For each category of public place, the time-cluster for observation was randomly selected. Thus, each sampled public place was visited only during the randomly selected time-cluster (Table 1). If the public place was closed or had shifted, then the existing trade in those premises was observed. If there was none, a new public place was selected randomly from the sampling frame and observations were made during the same time-cluster.

Among the sampled public places, 35\% were hotels, $25 \%$ were workplaces, $17 \%$ were educational institutions and $8.5 \%$ were hospitals (Table 2). Hospitals ranging from medical clinics, dental clinics, nursing homes, acupuncture clinics, Ayurveda hospital, eye hospital, 2 major governmental hospitals and 1 private hospital were observed. Three theaters and a mall constituted the remaining observed places. Two 


\section{Research paper}

Table 1. Sampling distribution of time clusters and category of public places

\begin{tabular}{|c|c|c|c|c|c|c|c|}
\hline \multirow{2}{*}{$\begin{array}{l}\text { Category of public } \\
\text { place }\end{array}$} & \multirow{2}{*}{$\begin{array}{l}\text { Total number of } \\
\text { public places }\end{array}$} & \multirow[t]{2}{*}{ Samplesize $(\%)$} & \multicolumn{5}{|c|}{ Public places sampled during each time cluster (21-hour clock) } \\
\hline & & & $9-11.59$ & $12-14.59$ & $15-17.59$ & $18-20.59$ & $21-23$ \\
\hline Accommodation & 443 & $36(9.9)$ & 12 & 12 & 3 & 5 & 4 \\
\hline Eateries & 1573 & $126(34.8)$ & 18 & 34 & 26 & 43 & 5 \\
\hline Work places & 1130 & $91(25.1)$ & 24 & 34 & 33 & 0 & 0 \\
\hline Educational institutions & 763 & $60(16.6)$ & 23 & 32 & 5 & 0 & 0 \\
\hline Government offices & 177 & $14(3.9)$ & 3 & 4 & 7 & 0 & 0 \\
\hline Hospital buildings & 384 & $31(8.6)$ & 8 & 0 & 03 & 17 & 0 \\
\hline Shopping malls & 10 & $1(0.3)$ & 1 & 0 & 0 & 0 & 0 \\
\hline Movie theatres & 27 & $3(0.8)$ & 2 & 0 & 1 & 0 & 0 \\
\hline Total & 4507 & $362(100)$ & 91 & 116 & 78 & 65 & 9 \\
\hline
\end{tabular}

\section{Table2. Sampling distribution with subcategories of public} places

\begin{tabular}{|c|c|c|c|}
\hline Slno & $\begin{array}{l}\text { Category and } \\
\text { subcategory of public } \\
\text { places }\end{array}$ & Total $(\%)$ & Sampled $(\%)$ \\
\hline 1 & Hotels & $1573(34.9)$ & $126(34.8)$ \\
\hline 2 & Accommodation facility & $443(9.8)$ & $36(9.9)$ \\
\hline 3 & Work places/industries & $1130(25.1)$ & $91(25.1)$ \\
\hline 4 & Educational institutions & $763(16.9)$ & $60(16.6)$ \\
\hline 5 & Government offices & $177(3.9)$ & $14(3.9)$ \\
\hline 6 & $\begin{array}{l}\text { Hospitals (public } \& \\
\text { private) } *\end{array}$ & $384(8.5)$ & $31(8.6)$ \\
\hline 7 & Shopping malls & $10(0.3)$ & $1(0.3)$ \\
\hline 8 & $\begin{array}{l}\text { Theatres/movie halls/ } \\
\text { cinema halls }\end{array}$ & $27(0.6)$ & $3(0.8)$ \\
\hline TOTAL & & 4507 & 362 \\
\hline
\end{tabular}

*Includes two clinics and nursing homes that were outside the BBMP area and hence excluded from final analysis.

clinics and one private nursing home were outside the boundary of BBMP South Zone and hence excluded.

\section{Data collection}

Data collection had two parts; the observation of public places, and the interview of persons responsible for compliance (PRCs) in the respective public place and authoried officers (AOs) for awareness to the smoke-free legislation. The key item that was recorded during the observation visit was whether any smoking was observed in non-smoking areas. Additional information that serves as an indicator of noncompliance, for example, the presence of cigarette butts, ashtrays or matches, was also gathered. Public places were observed with the help of senior and junior health inspectors of BBMP.
Compliance to Section 4 of COTPA was assessed using the following criteria:

1. Presence of 'No Smoking' signages as per the provisions of the Act at appropriate places.

2. No person is smoking within the public place during the period of observation.

3. Absence of indirect evidence of smoking, like ashtrays, cigarette butts, and matches during the visit.

4. Presence of a designated smoking-area as per the Act (only for those public places required to have a DSA, such as hotel or accommodation facilities having 30 or more rooms, restaurants or eateries having a seating capacity of 30 persons or more and airports $)^{15}$.

Data were collected by the investigators using Schedules 1, 2 and 3 adapted from the guide on 'Assessing Compliance with Smoke-Free Laws' developed jointly by the Campaign for Tobacco-Free Kids, Johns Hopkins Bloomberg School of Public Health and International Union against Tuberculosis and Lung Disease ${ }^{14}$. These Schedules have a standardized observational and interview data-collection format with items having yes/no options. These reflect the awareness about COTPA among PRC and AO, educated efforts made by them, acceptances or rejections, challenges or difficulties faced by them in implementing the Act, efforts and further course of actions adopted to implement the Act. It has items that reflect the key provisions of the law that were assessed. Schedule 1 is an interview cum observation Schedule for public places. Schedules 2 and 3 consist of questions for the PRCs and AOs of the COTPA Act, respectively. The investigators collected data between October and December 2014, after obtaining written informed consent from PRCs (Schedules 1 and 2) and AOs (Schedule 3). PRCs from all the sampled public places were interviewed using Schedule 2. All AOs 
Table 3. Compliance of public places to various aspects of Section 4 of COTPA in Bengaluru, 2015

\begin{tabular}{|c|c|c|}
\hline Compliance & Number $n=359$ & Percentage \\
\hline \multicolumn{3}{|l|}{ Signage-related compliance ${ }^{a}$} \\
\hline $\begin{array}{l}\text { Public places having 'Smoking not } \\
\text { permitted' signage }\end{array}$ & 108 & 30.9 \\
\hline $\begin{array}{l}\text { Sign boards partially complied as per } \\
\text { COTPA }\end{array}$ & 101 & 93.5 \\
\hline $\begin{array}{l}\text { Sign boards fully complied as per } \\
\text { COTPA }\end{array}$ & 7 & 6.5 \\
\hline \multicolumn{3}{|l|}{ Smoking-related compliance ${ }^{b}$} \\
\hline $\begin{array}{l}\text { People found smoking in the non- } \\
\text { smoking area at the time of visit }\end{array}$ & 13 & 3.9 \\
\hline Cigarette butts visible & 47 & 13 \\
\hline $\begin{array}{l}\text { Ashtrays or matches visible in the } \\
\text { non-smoking area }\end{array}$ & 22 & 6 \\
\hline \multicolumn{3}{|c|}{ Compliance related to designated smoking-area $(n=65)$} \\
\hline $\begin{array}{l}\text { Public places having designated } \\
\text { smoking-area }\end{array}$ & 10 & 15.3 \\
\hline $\begin{array}{l}\text { Public places with designated } \\
\text { smoking-area as open area }\end{array}$ & 6 & 1.67 \\
\hline $\begin{array}{l}\text { Public places with designated } \\
\text { smoking-area as a room }\end{array}$ & 4 & 1.1 \\
\hline \multicolumn{3}{|l|}{ Overall compliance* } \\
\hline Full compliance & 6 & 1.9 \\
\hline Partial compliance & 101 & 28.1 \\
\hline No compliance & 252 & 70 \\
\hline \multicolumn{3}{|c|}{$\begin{array}{l}\text { a } n=108 .{ }^{b} \text { multiple responses possible. * A public place was considered } \\
\text { fully compliant when 'No Smoking' signages were as per the guidelines of the } \\
\text { Act, no person was observed to be smoking during the period of observation, } \\
\text { absence of indirect evidence of smoking, like ash trays, cigarette butts, } \\
\text { matches, etc. and presence or absence of designated smoking-area as per } \\
\text { the Act. When none of the criteria was fulfilled, then the public place was } \\
\text { considered as 'No Compliance'. When some of the criteria were fulfilled, it } \\
\text { was considered partially compliant. }\end{array}$} \\
\hline
\end{tabular}

coming under the jurisdiction of South Zone BBMP were interviewed using Schedule 3.

All data were entered on a password-protected excel worksheet. Descriptive statistics like frequencies for qualitative variables and proportions for quantitative variables were drawn from the observations and interviews done. Categorization of compliance of public places was done as: full compliance meaning all the above criteria were fulfilled (100\%), no compliance meaning none of the above criteria was fulfilled $(0 \%)$, and partial compliance meaning some of the criteria were fulfilled (0 to $100 \%$ ).

Prior administrative approvals were obtained from appropriate authorities including the police and commissioner of BBMP. Ethical approval for the study was obtained by the Ethics Committee of the National Institute of Mental Health and Neuro Sciences (NIMHANS).

\section{Findings}

About one-third of the public places observed had partially complied with the provisions of COTPA Act (Table 3). A large proportion of them (70\%) did not comply with any of the provisions of the Act (no signage; violations with respect to evidence of smoking during observation; cigarette butts, ashtrays etc. were seen). Full compliance was seen only in six (1.9\%) public places.

There were about 65 public places that had to comply with having a designated smoking-area (DSA), but only 10 (15.3\%) had DSA. Among the 4 designated smoking-rooms, 2 had their access closed to the non-smoking area and had a vent (data not shown). Compared to other public places, almost half of the eateries had 'No Smoking' signage. However, nearly half (46.8\%) were not as per the Act (data not shown).

Most persons responsible for compliance (93.3\%) were aware of the existence of the smoke-free law in public places (Table 4). They opined that the Act is to ban smoking in public places. Very few (16.4\%) knew that the provisions included

Table 4. Awareness of Section 4 of COTPA Act among persons responsible for compliance at public places, SouthZone BBMP, 2015

$\begin{array}{lcc} & \text { Number (n 359) } & \text { Percentage } \\ \begin{array}{l}\text { Persons aware of the smoke-free law } \\ \text { in a public place }\end{array} & 335 & 93.3 \\ \begin{array}{l}\text { Public places with a formal policy on } \\ \text { smoking }\end{array} & 24 & 6.7 \\ \text { Awareness of provisions of the coTPA } & & \\ \begin{array}{l}\text { Smoking is banned in public places } \\ \text { Smoking is banned in public places, }\end{array} & 276 & 76.9 \\ \text { and offenders can be penalized } & 59 & 16.4 \\ \text { Not aware of the law } & 24 & 6.7 \\ \begin{array}{l}\text { Efforts undertaken to implement the } \\ \text { Act }\end{array} & 299 & 83.3 \\ \text { Type of efforts undertaken (n=299) } & & \\ \text { Oral warning not to smoke } & 191 & 63.8 \\ \text { Display of 'No smoking' Signboards } & 108\end{array}$

Responses by the staff /visitors/ employees and others to the educational efforts

Positive $252 \quad 84.3$

Negative

4

1.3

Mixed

Encountered challenges in keeping

71

the environment smoke-free

$(n=358)$ *

Type of challenges encountered $(n=71)$

Non-compliance to COTPA guidelines

Efforts to resolve the difficulties

51

71.8 
a penalty for those who violated the provisions of the law. A majority (84\%) of the persons responsible for compliance undertook educational efforts, which included mostly oral warnings not to smoke (63.8\%) and display of 'No Smoking' signboards (36.2\%). Mostly, they received a positive response to their efforts (84.3\%).

Every authorized officer among health and police were aware of the smoke-free Act (Table 5). Among the authorized police officers, the majority (96\%) were aware that Section 4 of the COTPA Act involves a smoking ban in public places and that there is a penalty for offenders. All of them were aware that they were authorized to penalize offenders.

Table 5. Awareness and enforcement of Section 4 of COTPA act among authorized officers, South Zone BBMP, 2015

\begin{tabular}{|c|c|c|}
\hline & Health* $(n-30)$ & $\begin{array}{l}\text { Police }^{* *} \\
(n-25)\end{array}$ \\
\hline Aware of smoke-free Act & $30(100.0)$ & $25(100.0)$ \\
\hline \multicolumn{3}{|l|}{ Awareness of provisions of the COTPA } \\
\hline Smoking is banned in public places & $20(66.7)$ & $1(4.0)$ \\
\hline $\begin{array}{l}\text { Smoking is banned in public places, } \\
\text { and offenders can be penalized }\end{array}$ & $10(33.3)$ & $24(96.0)$ \\
\hline $\begin{array}{l}\text { Aware about authorization of persons } \\
\text { to penalize }\end{array}$ & 0 & $25(100.0)$ \\
\hline \multicolumn{3}{|c|}{ Enforcement activities undertaken by authorized officers } \\
\hline Penalized the offenders & 0 & $25(96.0)$ \\
\hline \multicolumn{3}{|c|}{ Penalties imposed in past one month (in Indian Rupees) } \\
\hline $1-50$ & 0 & $13(52.0)$ \\
\hline $51-100$ & 0 & $5(20.0)$ \\
\hline Above 100 & 0 & $7(28.0)$ \\
\hline $\begin{array}{l}\text { Encountered challenges while } \\
\text { enforcing the Act }\end{array}$ & $19(63.3)$ & $23(92.0)$ \\
\hline $\begin{array}{l}\text { Public awareness efforts } \\
\text { undertaken }\end{array}$ & $25(83.3)$ & $24(96.0)$ \\
\hline $\begin{array}{l}\text { Type of public awareness efforts } \\
\text { undertaken }\end{array}$ & $n=25$ & $n=24$ \\
\hline Notices to display signboards & $9(36.0)$ & $18(75.0)$ \\
\hline Oral warning to public not to smoke & $16(64.0)$ & $6(25.0)$ \\
\hline \multicolumn{3}{|l|}{ Responses to efforts undertaken } \\
\hline Positive & $3(12.0)$ & $1(4.2)$ \\
\hline Mixed & $22(88.0)$ & $23(95.8)$ \\
\hline
\end{tabular}

*Includes four Food Safety officers; ${ }^{* *}$ Includes one Excise official;

However, none of the authorized health officers was aware that they were authorized to penalize offenders. Two-thirds of the health officers and a large majority (92\%) of police officers encountered difficulties while enforcing the Act. This includes passive resistance and arguments with the persons enforcing the Act. Nearly all the authorized officers undertook public awareness activities about the provisions of the Act.

\section{DISCUSSION}

This is the first population-based representative formal assessment of compliance to Section 4 of the Cigarettes and Other Tobacco Products (COTPA) Act 2008 in Bengaluru city. Full compliance was noted among a meager $2 \%$ of the public places. The majority of the public places in South Zone BBMP did not comply with Section 4 of the COTPA Act. The majority of persons responsible for compliance of COTPA in public places and all authorized officers were aware of the smoke-free law. Most of those who were aware made efforts to comply with the COTPA Act. Most efforts were educational in nature and about one-fifth reported encountering difficulties to implement the Act. One-third of public places had signage that partially complied with COTPA guidelines. A few public places, which were supposed to have designated smokingareas, complied. Enforcement in terms of penalizing the offenders was done only by the police. Authorized health officers and persons responsible for compliance in public places were not aware of the provisions under the Act; that persons responsible for compliance of COTPA in public places can penalize the offenders. Our study shows that authorized officers and persons responsible for compliance encountered challenges in implementing the Act and in ensuring the area smoke-free.

Studies have concluded that Smoke-Free legislation is the most effective method for reducing exposure to second-hand smoke (SHS $)^{16-19}$. Comprehensive smoke-free air laws are effective in reducing indoor air pollution from second-hand tobacco smoke ${ }^{20}$. Section 4 of the COTPA Act specifically deals with preventing second-hand smoke to non-smokers. The implementation of the Act is vital given the high attributable risk for any malignancies and other non-communicable diseases associated with smoking ${ }^{21-24}$.

Our findings are similar with those of other studies on compliance assessment done in other cities of India ${ }^{25}$. A study done in Chennai reported low compliance of smoke-free laws in restaurants, schools, and colleges ${ }^{26}$. A study done in Himachal Pradesh reported that $42.8 \%$ of public places had signage, smoking was observed in $15.8 \%$ of public places, and in $16.3 \%$ of the public places there were smoking accessories such as ashtrays, matchboxes and lighters ${ }^{25}$. Tobacco litter, like cigarette butts, was present in $35.3 \%$ of the public places. Our study also reported that awareness about the smoke-free Act among persons responsible for compliance was $93 \%$, which is similar to the study done in Mohali, Punjab ${ }^{10}$. Most of the studies report compliance among restaurants, educational institutions and hospital buildings, by observation. In addition to observation of public places for signs of active smoking and 
smoking aids, we also interviewed persons responsible for compliance, as well as authorized officers to enforce COTPA in public places. This is an improvement from previous studies.

Improving on the methodology of previous studies, the present study is representative since we adopted time-location sampling, ensuring representativeness of both location and time. This allows adjustment for any diurnal variation in smoking habits and use of public places, if present. Our study also used the standardized checklist developed jointly by the Campaign for Tobacco-Free Kids, Johns Hopkins Bloomberg School of Public Health and International Union against Tuberculosis and Lung Disease utilizing the guide 'Assessing compliance with smoke-free law'14, thus ensuring comparability with other studies.

\section{Limitations}

Our study is not without limitations. Firstly, we have utilized senior health officials of BBMP along with the letters of administrative approvals from officials to gain access to public places. This might have influenced the persons responsible for compliance of the Act to respond favourably to the interview. However, observation of public places, informed consent, explanation of study purposes and procedures are likely to reduce this information bias. Secondly, only registered licensed public-places were included in the study. Since licensing involves complying with the regulations of the Act, it is likely that these places (licensed) are more likely to comply compared to unlicensed places. Thus, overall compliance within the South Zone of Bengaluru would be less than what was found in our study. The results of our study are applicable only to public places defined within the study and not generalizable to other public places, like open auditoriums, stadiums, railway stations, bus stops/stands, mass media transport systems and public parks. Ideally, these public places also should have been included.

\section{CONCLUSIONS}

Persons responsible for compliance in public places and authorized officers are the key to the success of implementing COTPA. In addition, effective implementation would help to reduce social acceptance, deter initiation and reduce consumption. Our study reports challenges faced in implementing the Act, especially among persons responsible for compliance in public places, similar to a study in China ${ }^{24}$. Compliance is a behavioral issue and the first step towards compliance is making the PRCs aware of the Act.

Thus, awareness about the Act, importance of effective implementation on the health of people, awareness that even
PRCs can penalize the offenders in public places, is likely to contribute to an increase in compliance and social acceptance. This will contribute to preventing the ill effects of SHS, thereby increasing health improvement, which is the main purpose of COTPA Section 4. Similar to our study, the protection from SHS exposure in restaurants, pubs and bars is reported to be very low in most countries ${ }^{28,29}$. Our study results imply that stronger implementation of COTPA guidelines could be done using a multipronged approach. Constant efforts to create awareness regarding the public-health aspects of the smoke-free Act in public places are needed. Firstly, increasing awareness among persons responsible for compliance and authorized officers to ensure better compliance to the Act, and secondly by educating the public at large on the existence of the law and the health benefits to them and others. These would probably reduce the resistance faced by the persons responsible for compliance and authorized officers.

To achieve maximum gains, different strategies need to be adapted. A series of sensitization programs among authorized officers and persons responsible for compliance, and publichealth campaigns to increase awareness of the public-health benefits of the Smoke-Free law, are more likely to smoothen enforcement, reduce resistance among stakeholders and eventually ensure compliance. Regular appraisals about the public-health aspects of the anti-smoking law might ensure compliance with the COPTA Act. Such an appraisal can be done if the current status of awareness, compliance, and enforcement is known. Our study reported the compliance levels in a cosmopolitan city like Bengaluru. Similar studies in rural areas will shed light on the rural aspects of compliance. We strongly recommend studies to be undertaken about other Sections of the COTPA that are of public-health importance (Sections $5 \& 6$ ), in rural and urban areas, to get a comprehensive assessment of compliance of the health-related Sections of the COTPA Act.

\section{REFERENCES}

1 Tobacco use fact sheet WHO. Available at: http://www.who.int/nmh/ publications/fact_sheet_tobacco_en.pdf (accessed September 2016).

2. Economic Burden of Tobacco Related Diseases in India. Available at: http://www.searo.who.int/india/topics/tobacco/economic_burden_ of_tobacco_related_diseases_in_india_executive_summary.pdf (accessed September 2016).

3. Health worker Guide. Available at: http://www.mohfw.gov.in/ WriteReadData/1892s/Health\%20Worker\%20Guide.pdf (accessed September 2016).

4. The Health Consequences of Smoking-50 Years of Progress A Report of the Surgeon General. Available at: http://www.surgeongeneral. gov/library/reports/50-years-of-progress/full-report.pdf (accessed September 2016).

5. Health CO on S and. Smoking and Tobacco Use; Fact Sheet; Secondhand Smoke . Smoking and Tobacco Use. Available at: http:// 
www.cdc.gov/tobacco/data_statistics/fact_sheets/secondhand_ smoke/general_facts/ (accessed September 2016).

6. WHO | WHO report on the global tobacco epidemic, 2011. WHO. Available at: http://www.who.int/tobacco/global_report/2011/en/ (accessed September 2016).

7. WHO | Second-hand smoke [Internet]. WHO. Available at: http://www.who.int/gho/phe/secondhand_smoke/en/ (accessed September 2016).

8. GATS India. Global Adult Tobacco Survey, India 2009-2010 [Internet]. Available at: http://mohfw.nic.in/WriteReadData/ 1892s/1455618937GATS\%20India.pdf (accessed September 2016).

9. Guidelines for implementation of Smoke Free Rules (Section 4) and Tobacco Free Educational Institutions (Section 6) of COTPA 2003 [Internet]. Available at: http://pbhealth.gov.in/ GUIDELINES\%20FOR\%20IMPLEMENTATION\%200F\%20 COTPA.pdf (accessed September 2016).

10. Goel S, Ravindra K, Singh RJ, Sharma D: Effective smoke-free policies in achieving a high level of compliance with smoke-free law: experiences from a district of North India. Tob Control. 2014;23(4):291-4.

doi: 10.1136/tobaccocontrol-2012-050673

11. Tripathy JP, Goel S, Patro BK. Compliance monitoring of prohibition of smoking (under section- 4 of COTPA) at a tertiary health-care institution in a smoke-free city of India. Lung India Off Organ Indian Chest Soc. 2013;30(4):312-5.

doi: 10.4103/0970-2113.120607

12. Resource Guide: Time Location Sampling (TLS) 2nd Edition. Available at: http://globalhealthsciences.ucsf.edu/sites/default/files/ content/pphg/surveillance/modules/global-trainings/tls-res-guide2nd-edition.pdf (accessed September 2016).

13. Epi InfoTM | CDC [Internet]. Available from: https://www.cdc.gov/ epiinfo/index.html (accessed September 2016).

14. Assessing Compliance with Smoke-Free Laws May 2014 A "How-to" Guide for Conducting Compliance Studies Second Edition. Available at: http://www.theunion.org/what-we-do/publications/technical/ english/compliance-guide_v4smallerfile.pdf (accessed September 2016).

15. COTPA Sec 4: Prohibition of Smoking in Public Places. Available at: http://www.cancerfoundationofindia.org/activities/tobacco-control/ resource-material/pdf/sec-4-prohibition-of-smoking-in-publicplaces.pdf (accessed September 2016).

16. López MJ, Fernàndez E, Gorini G, Moshammer H, Polanska K, Clancy L, et al. Exposure to Secondhand Smoke in Terraces and Other Outdoor Areas of Hospitality Venues in Eight European Countries. PLOS ONE. 2012 Aug 1;7(8):e42130. doi: 10.1371/journal.pone.0042130

17. Kumar R, Goel S, Harries AD, Lal P, Singh RJ, Kumar AMV, et al. How good is compliance with smoke-free legislation in India? Results of 38 subnational surveys. Int Health. 2014 Sep;6(3):189-95. doi: 10.1093/inthealth/ihu028

18. Naiman AB, Glazier RH, Moineddin R. Is there an impact of public smoking bans on self-reported smoking status and exposure to secondhand smoke? BMC Public Health. 2011;11:146.

10.1186/1471-2458-11-146

19. Lee K, Hahn EJ, Robertson HE, Lee S, Vogel SL, Travers MJ. Strength of smoke-free air laws and indoor air quality. Nicotine Tob Res. 2009 Apr;11(4):381-6. doi: $10.1093 / \mathrm{ntr} / \mathrm{ntp} 026$
20. Shopland DR. Tobacco use and its contribution to early cancer mortality with a special emphasis on cigarette smoking. Environ Health Perspect. 1995 Nov;103(Suppl 8):131-42. doi: 10.1289/ehp.95103s8131

21. D'Agostino RB, Vasan RS, Pencina MJ, Wolf PA, Cobain M, Massaro JM, et al. General cardiovascular risk profile for use in primary care: the Framingham Heart Study. Circulation. 2008 Feb 12;117(6):743-53. doi: 10.1161/circulationaha.107.699579

22. Vineis P, Caporaso N. Tobacco and cancer: epidemiology and the laboratory. Environ Health Perspect. 1995 Feb;103(2):156-60. doi: 10.1289/ehp.95103156

23. Bosetti C, Gallus S, Peto R, Negri E, Talamini R, Tavani A, et al. Tobacco smoking, smoking cessation, and cumulative risk of upper aerodigestive tract cancers. Am J Epidemiol. 2008 Feb 15;167(4):468-73.

doi: $10.1093 / \mathrm{aje} / \mathrm{kwm} 318$

24. Hu T-W, Lee AH, Mao Z. WHO Framework Convention on Tobacco Control in China: barriers, challenges and recommendations. Glob Health Promot. 2013 Dec;20(4):13-22. doi: $10.1177 / 1757975913501910$

25. Kumar R, Lal P, Satyanarayana S, Singh R, Wilson N, Chauhan G. Assessing compliance to smoke-free legislation: results of a sub-national survey in Himachal Pradesh, India. WHO SouthEast Asia J Public Health. 2013;2(1):52. doi: 10.4103/2224-3151.115843

26. Kaur P, Thomas DR, Govindasamy E, Murhekar MV. Monitoring smoke-free laws in restaurants and educational institutions in Chennai, India. Natl Med J India. 2014 Apr;27(2):76-8.

27. Goel S, Singh R, D S, A S. Public opinion about smoking and smoke free legislation in a district of North India. Indian J Cancer. 2014;51(3):330. doi: 10.4103/0019-509x.146788

28. Fernàndez E, Fu M, Pascual JA, López MJ, Pérez-Ríos M, Schiaffino A, et al. Impact of the Spanish smoking law on exposure to second-hand smoke and respiratory health in hospitality workers: a cohort study. PloS One. 2009;4(1):e4244.

doi: 10.1371/journal.pone.0004244

29. Gleich F, Mons U, Pötschke-Langer M. Air Contamination Due to Smoking in German Restaurants, Bars, and Other Venues-Before and After the Implementation of a Partial Smoking Ban. Nicotine Tob Res. 2011 May 26:ntr099.

doi: 10.1093/ntr/ntr099

\section{ACKNOWLEDGEMENTS}

The authors would like to acknowledge the support of Drs Girish, Gautham MS, Senthil AR, Aravind $B A$, Parthibane $S$ and staff of the Department of Epidemiology, NIMHANS, in the conduct of this study.

Drs PB and GG

were involved in conceptualisation, planning, supervision of data collection, analysis and interpretation of study results. Dr. MVK was involved in data collection, entry, analyses and reporting. Drs PB and MVK were involved in writing the manuscript. All authors were involved in critically reviewing the article for its content and approved the final manuscript.

CONFLICT OF INTERESTS

The authors have completed and submitted the ICMJE Form for Disclosure of Potential Conflicts of Interest and none was reported.

\section{FUNDING}

There was no source of funding for this research.

PROVENANCE AND PEER REVIEW

Not commissioned; externally peer reviewed 